\title{
Article
}

\section{Reduced CD4 T Lymphocytes in Lymph Nodes of the Mouse Model of Autism Induced by Valproic Acid}

Baronio, Diego, Bauer-Negrini, Guilherme, Castro, Kamila, DellaFlora Nunes, Gustavo, Riesgo, Rudimar, Mendes-da-Cruz, Daniella Arêas, Savino, Wilson, Gottfried, Carmem and Bambini-Junior, Victorio

Available at http://clok.uclan.ac.uk/24078/

Baronio, Diego, Bauer-Negrini, Guilherme, Castro, Kamila, Della-Flora Nunes, Gustavo, Riesgo, Rudimar, Mendes-da-Cruz, Daniella Arêas, Savino, Wilson, Gottfried, Carmem and Bambini-Junior, Victorio ORCID: 0000-0002-8590-6770 (2018) Reduced CD4 T Lymphocytes in Lymph Nodes of the Mouse Model of Autism Induced by Valproic Acid. Neuroimmunomodulation . ISSN 1021-7401

It is advisable to refer to the publisher's version if you intend to cite from the work. http://dx.doi.org/10.1159/000491395

For more information about UCLan's research in this area go to http://www.uclan.ac.uk/researchgroups/ and search for <name of research Group>.

For information about Research generally at UCLan please go to http://www.uclan.ac.uk/research/

All outputs in CLoK are protected by Intellectual Property Rights law, including Copyright law. Copyright, IPR and Moral Rights for the works on this site are retained by the individual authors and/or other copyright owners. Terms and conditions for use of this material are defined in the policies page. 
Reduced CD4 T lymphocytes in lymph nodes of the mice model of autism induced by valproic acid.

Diego Baronio ${ }^{1,2^{*}}$, Guilherme Bauer-Negrini ${ }^{1,3,4^{*}}$, Kamila Castro ${ }^{1,2}$, Gustavo

Della-Flora Nunes ${ }^{1,3}$, Rudimar Riesgo ${ }^{1,2,4}$, Daniella Arêas Mendes-da-Cruz ${ }^{4,5}$, Wilson Savino ${ }^{4,5}$, Carmem Gottfried ${ }^{1,3,4}$, Victorio Bambini-Junior ${ }^{1,4,6}$

*These authors contributed equally to this work

1. Translational Group in Autism Spectrum Disorder - GETTEA, Clinical Hospital of Porto Alegre, Porto Alegre, Brazil

2. Child Neurology Unit, Clinical Hospital of Porto Alegre, Federal University of Rio Grande do Sul, Porto Alegre, Brazil.

3. Department of Biochemistry, Federal University of Rio Grande do Sul, Porto Alegre, RS, Brazil.

4. Brazilian National Institute of Science and Technology on neuroimmunomodulation (INCT-NIM), Rio de Janeiro, Brazil

5. Laboratory on Thymus Research, Oswaldo Cruz Institute, Oswaldo Cruz Foundation, Rio de Janeiro, Brazil.

6. School of Pharmacy and Biomedical Sciences, University of Central Lancashire, Preston, UK.

Corresponding authors:

DB diego.baronio@helsinki.fi

VB VBambini-Junior@uclan.ac.uk

Short title: VPA decreases $C D 4^{+} \mathrm{T}$ cells numbers in lymph nodes Keywords: ASD, autism, VPA, lymph nodes 


\section{Abstract}

Objective. Considering the potential role of lymphocytes in the pathophysiology of autism spectrum disorders we aimed to evaluate possible alterations of T-cell pools in lymphoid organs of an animal model of autism induced by valproic acid (VPA). Pregnant Swiss mice received a single intraperitoneal injection of 600 $\mathrm{mg} / \mathrm{kg}$ of VPA (VPA group) or saline (control group) on day 11 of gestation. Male animals of the offspring were euthanized on postnatal day 60 for removal of thymuses, spleens, and a pool of inguinal, axillary and brachial lymph nodes. Cellularity was evaluated, and flow cytometry analysis was performed on cell suspensions incubated with mouse antibodies anti-CD3-FITC, anti-CD4-PE and anti-CD8-PE-Cy7. We observed that the prenatal exposure to VPA induced a reduction in the numbers of $\mathrm{CD} 3+\mathrm{CD} 4+\mathrm{T}$ cells in their lymph nodes when compared to the control animals. This was rather specific, since it was not seen in the thymus or spleen. The consistent decrease in the number of CD4+ T-cells in subcutaneous lymph nodes of mice from the animal model of autism may be related to the allergic symptoms frequently observed in ASD. Yet, further research is necessary to characterize the immunological patterns in ASD and its connection with the pathophysiology of this disorder. 
Autism spectrum disorder (ASD) is a complex developmental condition characterized by impairments in social communication and interaction and repetitive patterns of behavior and interests [1]. Although its etiology is still unknown, both genetic and environmental factors are known to play key roles in ASD pathophysiology [2]. Recently, the involvement of the immune system [3] and neuroimmune interactions have been proposed as important etiological components of ASD [2]. In fact, many immunological alterations are common in ASD such as abnormal microglial growth and activation [4], family history of autoimmune diseases [5] and abnormal levels of inflammatory cytokines [6]. Also, food allergy is frequently present in ASD patients, with early- and late-phase reactions, promoting gastrointestinal and skin diseases and asthma [7]. More specifically, lymphocytic abnormalities were reported in ASD [8], including deficiency in $\mathrm{CD}^{+} \mathrm{T}$-cells. A case-control study including 30 Egyptian children (22 boys and 8 girls) with classic-onset autism, revealed that $C D 4^{+} C D 25^{\text {high }}$ regulatory T cells are deficient in children with ASD [9]. The authors found the frequency of autoimmune diseases among families of the ASD group was 53.3\% higher than the control group, pointing a familiar autoimmune background. These data corroborate with previous studies $[5,10,11]$ and indicate a significant association between the reduced number of $\mathrm{CD} 4{ }^{+} \mathrm{CD} 25^{\text {high }}$ regulatory $\mathrm{T}$ cells and both allergic manifestations and family history of autoimmunity.

Several studies reported abnormalities in T-lymphocytes in about $35 \%$ of ASD patients with decreased numbers of CD4+ T-cells and increased numbers of CD8+ T-cells [12]. Interestingly, in a double-blind study, autistic symptoms were diminished in $56 \%$ of the patients that were treated with naltrexone, an opiate antagonist [13]. This drug increased the number of T-helper inducers and 
reduced the number of T-cytotoxic suppressors, resulting in a normalization of the $\mathrm{CD} 4 / \mathrm{CD} 8$ ratio.

Furthermore, T cells appear to play a key role in many behavioral and cognitive processes [14,15], especially in social behavior modulation [16]. For instance, immune deficient mice exhibit an impairment in cognition and emotional behaviors, which has been attributed specifically to CD4+ $T$ cells [17] Impaired learning and memory was reported in severe combined immunodeficiency

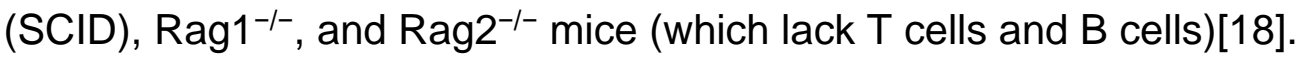

Prenatal exposure to valproic acid (VPA) in rodents triggers autistic-like morphological and behavioral outcomes [19]. This model has been developed based on the fact that maternal use of VPA during pregnancy is associated with increased risk of ASD by the children [20].

Immunological alterations such as thymic atrophy [21] and increased mRNA levels of proinflammatory cytokines in the spleen (after LPS challenge) were already described in this model [22], but data on the T-cells pools in the thymus and secondary lymphoid organs are absent. Here we investigated the status of $\mathrm{T}$ cell subsets in primary and secondary lymphoid organs, namely thymus, spleen and subcutaneous lymph nodes.

To this purpose, female Swiss mice (obtained from Federal University of Pelotas, Pelotas, Brazil) were housed in a 12-h light-dark cycle, with controlled temperature $\left(22 \pm 1{ }^{\circ} \mathrm{C}\right)$, water and food ad libitum. Pregnancy was determined by the presence of vaginal plug, and that was considered the day 0 of gestation. On day 11 of gestation pregnant mice received a single intraperitoneal injection of $600 \mathrm{mg} / \mathrm{kg}$ of VPA (Across Organics, New Jersey, USA) (VPA group) or saline (control group). Male animals of the offspring were anesthetized with isoflurane 
gas and exsanguinated on postnatal day 60 . The experimental groups consisted of 9 animals per group. The study was approved by the Research Ethics Committee of the Clinical Hospital of Porto Alegre (Porto Alegre, Brazil). For the cytofluorometric studies, cells from the thymus, spleen and subcutaneous lymph nodes (inguinal, axillary and brachial chains) were obtained after homogenizing the tissues with a tissue grinder and counted in Neubauer chambers. Suspensions containing $10^{6}$ cells were prepared, and incubated with fluorochrome-labeled rat anti-mouse antibodies anti-CD3-FITC (1:50), anti-CD4PE (1:50) and anti-CD8-PE-Cy7 (1:100) (BD Biosciences, San Jose, USA) for 20 min with $2 \%$ fetal bovine serum-PBS solution for 20 min at $4{ }^{\circ} \mathrm{C}$. Cells were then washed and analyzed by flow cytometry using the Attune ${ }^{\circledR}$ Acoustic Focusing Cytometer (Applied Biosystems, CA, USA), equipped with the Attune® Cytometric Software version 1.2.5.

Data were statistically analyzed using SPSS for Windows (SPSS Inc., Chicago, III., USA) and graphs were plotted with GraphPad Prism software. Results were expressed as means \pm standard error $(\mathrm{SE})$ and statistical comparisons were performed using multiple t-tests followed by Bonferroni correction. Samples were considered statistically different when $p$ value was $\leq 0.05$.

Prenatal exposure to valproic acid decreases CD4+ $T$ lymphocytes in subcutaneous lymph nodes of offspring

We first noticed that no differences between groups were found in terms lymphoid organ weight (Table 1). Moreover, no differences were observed in both immature (CD4-CD8- and CD4+CD8+), as well as mature (CD3+CD4+ CD8- or CD3+CD4CD8+ T-cell subsets in the thymus (Table 1). Similarly, no differences were found in spleen-derived $\mathrm{T}$ cell subsets (Table 1). Interestingly however, in 
subcutaneous lymph nodes, the numbers of $C D 3+C D 4+T$ cell subset were significantly reduced in VPA group (Figure 1B), whereas the corresponding percentage was increased (Figure 1C). The membrane density of CD3, CD4 and CD8, as ascertained by median fluorescent intensity (MFI) on T lymphocytes did not significantly differ between VPA and control groups (Supplementary Figure S1)

Considering that the etiology of ASD remains unknown, the association between this disorder and immunological disturbances is becoming more evident [3]. However, to date, it has not been elucidated whether immune disorders are causative of ASD or if ASD leads to immune alterations. Recently, more attention has been given to the postnatal immune imbalance of specific immune cell subsets, including $\mathrm{CD}^{+}$and $\mathrm{CD}^{+} \mathrm{T}$ cells. Reduced number of $\mathrm{T}$ cells in individuals with ASD, as well as an altered CD4+/CD8+ T-cell ratio was reported in 1986 [23] and in the following years abnormalities such as increased TNFa and decreased IL-10 production by T-cells, increased production of IL-17 [6,24], reduction of peripheral CD4+ [8] and dysregulation of Th1/Th2/Th17 T-cell pools [25] were all described in children with ASD.

Reports of allergic manifestations among individuals with ASD are common. For instance, experience of atopic diseases in early childhood was associated with a 3.40-fold increased risk of ASD [26]. In addition, higher frequency of atopic dermatitis, asthma, rhinitis and serum IgE have been demonstrated in children with Asperger compared to age-matched controls (87\% vs. 7\%) [27].

Exposure to VPA may lead to impairments in the proliferative process of lymphocytes in vitro [28], as well as to a drastic reduction in the number of these 
cells in lymph nodes, spleen and peripheral blood [29]. Furthermore, rats exposed prenatally to VPA display thymic atrophy [21].

An important aspect to be considered is the crosstalk between the mother and the embryo. In light of the neuroimmune influence on ASD pathophysiology and the in vitro effect of VPA on lymphocytes, we conceive that the maternal blood cells might be influenced by VPA, even upon a single injection protocol. Accordingly, the mother immune response could influence the neuroimmune system in the embryo, like a fingerprint, interfering in the neurodevelopment later on. This hypothesis, associated to epigenetic changes could explain how a single injection of VPA i.p. during pregnancy is capable to trigger behavioral-like autism in the offspring, with anatomic and molecular alterations in the nervous and immune systems through life. In the present work, no difference was found between thymuses weight and cellularity in mice from VPA and control groups. The discrepancy between those results can be ascribed to differences in the animal species studied and to the use of animals twice old as those reported by Schneider et al. [21].

Given the large amount of data supporting the role of immune responses in ASD, advances in deciphering the functional interplay between immune cells and ASD symptoms will likely provide vital insights into the mechanisms and potential therapy of neurodevelopmental disorders.

Conflicts of interest: The authors declare that there are no conflicts of interest.

\section{Acknowledgements}


This work was funded by the Brazilian National Institute of Science and Technology on Neuroimmunomodulation (INCT-NIM), Rio de Janeiro, Brazil; National Council of Scientific and Technological Development (CNPq); Brazilian Coordination for the Improvement of Higher Education Personnel (CAPES), Rio de Janeiro State Foundation for Funding Research (Faperj), Oswaldo Cruz Foundation (Fiocruz), Clinical Hospital of Porto Alegre (FIPE-HCPA), Fund for Structural Convergence (FOCEM) of MercoSur. 


\section{REFERENCES}

1 American Psychiatric Association: Diagnostic and Statistical Manual of Mental Disorders. American Psychiatric Association, 2013. DOI: 10.1176/appi.books.9780890425596

2 Gottfried C, Bambini-Junior V, Francis F, Riesgo R, Savino W: The impact of neuroimmune alterations in autism spectrum disorder. Front Psychiatry 2015;6:121.

3 Gesundheit B, Rosenzweig JP, Naor D, Lerer B, Zachor DA, Procházka V, et al.: Immunological and autoimmune considerations of Autism Spectrum Disorders. J Autoimmun 2013;44:1-7.

4 Morgan JT, Chana G, Pardo CA, Achim C, Semendeferi K, Buckwalter J, et al.: Microglial Activation and Increased Microglial Density Observed in the Dorsolateral Prefrontal Cortex in Autism. Biol Psychiatry 2010;68:368376.

5 Sweeten TL, Bowyer SL, Posey DJ, Halberstadt GM, McDougle CJ: Increased prevalence of familial autoimmunity in probands with pervasive developmental disorders. Pediatrics 2003 [cited 2017 Dec 20];112:e420.

6 Ashwood P, Krakowiak P, Hertz-Picciotto I, Hansen R, Pessah I, Van de Water J: Elevated plasma cytokines in autism spectrum disorders provide evidence of immune dysfunction and are associated with impaired behavioral outcome. Brain Behav Immun 2011;25:40-45.

7 Khakzad MR, Javanbakht M, Soltanifar A, Hojati M, Delgosha M, Meshkat M: The evaluation of food allergy on behavior in autistic children. Reports Biochem Mol Biol 2012 [cited 2017 Dec 20];1:37-42.

8 Yonk LJ, Warren RP, Burger RA, Cole P, Odell JD, Warren WL, et al.: CD4+ helper T cell depression in autism. Immunol Lett 1990 [cited 2017 Dec 20];25:341-5.

9 Mostafa GA, Al Shehab A, Fouad NR: Frequency of CD4+CD25 high Regulatory $\mathrm{T}$ Cells in the Peripheral Blood of Egyptian Children With Autism. J Child Neurol 2010;25:328-335.

10 Gehan Ahmed Mostafa GA, Awad El-Sayed Z, Mohamed Abd El-Aziz M, Farouk El-Sayed M: Serum Anti-Myelin-Associated Glycoprotein Antibodies in Egyptian Autistic Children. J Child Neurol 2008;23:14131418. 
11 Comi AM, Zimmerman AW, Frye VH, Law PA, Peeden JN: Familial clustering of autoimmune disorders and evaluation of medical risk factors in autism. J Child Neurol 1999;14:388-94.

12 Ashwood P, Krakowiak P, Hertz-Picciotto I, Hansen R, Pessah IN, Van de Water J: Altered T cell responses in children with autism. Brain Behav Immun 2011;25:840-849.

13 Scifo R, Cioni M, Nicolosi A, Batticane N, Tirolo C, Testa N, et al.: Opioidimmune interactions in autism: behavioural and immunological assessment during a double-blind treatment with naltrexone. Ann Ist Super Sanita 1996 [cited 2018 Jan 26];32:351-9.

14 Radjavi A, Smirnov I, Kipnis J: Brain antigen-reactive CD4+ T cells are sufficient to support learning behavior in mice with limited $T$ cell repertoire. Brain Behav Immun 2014;35:58-63.

15 Derecki NC, Cardani AN, Yang CH, Quinnies KM, Crihfield A, Lynch KR, et al.: Regulation of learning and memory by meningeal immunity: a key role for IL-4. J Exp Med 2010;207:1067-1080.

16 Filiano AJ, Xu Y, Tustison NJ, Marsh RL, Baker W, Smirnov I, et al.: Unexpected role of interferon- $\gamma$ in regulating neuronal connectivity and social behaviour. Nature 2016;535:425-429.

17 Radjavi A, Smirnov I, Derecki N, Kipnis J: Dynamics of the meningeal CD4(+) T-cell repertoire are defined by the cervical lymph nodes and facilitate cognitive task performance in mice. Mol Psychiatry 2014;19:5313.

18 Marin I, Kipnis J: Learning and memory ... and the immune system. Learn Mem 2013;20:601-6.

19 Bambini-Junior V, Zanatta G, Della Flora Nunes G, Mueller de Melo G, Michels $M$, Fontes-Dutra M, et al.: Resveratrol prevents social deficits in animal model of autism induced by valproic acid. Neurosci Lett 2014;583:176-81.

20 Christensen J, Grønborg TK, Sørensen MJ, Schendel D, Parner ET, Pedersen LH, et al.: Prenatal Valproate Exposure and Risk of Autism Spectrum Disorders and Childhood Autism. JAMA 2013;309:1696.

21 Schneider T, Roman A, Basta-Kaim A, Kubera M, Budziszewska B, Schneider $\mathrm{K}$, et al.: Gender-specific behavioral and immunological 
alterations in an animal model of autism induced by prenatal exposure to valproic acid. Psychoneuroendocrinology 2008;33:728-740.

Lucchina L, Depino AM: Altered Peripheral and Central Inflammatory Responses in a Mouse Model of Autism. Autism Res 2014;7:273-289.

23 Warren RP, Margaretten NC, Pace NC, Foster A: Immune abnormalities in patients with autism. J Autism Dev Disord 1986 [cited 2018 Jan 26];16:18997.

24 Akintunde ME, Rose M, Krakowiak P, Heuer L, Ashwood P, Hansen R, et al.: Increased production of IL-17 in children with autism spectrum disorders and co-morbid asthma. J Neuroimmunol 2015;286:33-41.

25 Ahmad SF, Zoheir KMA, Ansari MA, Nadeem A, Bakheet SA, AL-Ayadhi LY, et al.: Dysregulation of Th1, Th2, Th17, and T regulatory cell-related transcription factor signaling in children with autism. Mol Neurobiol 2017;54:4390-4400.

26 Chen M-H, Su T-P, Chen Y-S, Hsu J-W, Huang K-L, Chang W-H, et al.: Is atopy in early childhood a risk factor for ADHD and ASD? A longitudinal study. J Psychosom Res 2014;77:316-321.

27 Magalhães ES, Pinto-Mariz F, Bastos-Pinto S, Pontes AT, Prado EA, deAzevedo LC: Immune allergic response in Asperger syndrome. J Neuroimmunol 2009;216:108-12.

28 Zhang Z, Zhang Z-Y, Wu Y, Schluesener HJ: Valproic acid ameliorates inflammation in experimental autoimmune encephalomyelitis rats. Neuroscience 2012;221:140-150.

29 Dowdell KC, Pesnicak L, Hoffmann V, Steadman K, Remaley AT, Cohen JI, et al.: Valproic acid (VPA), a histone deacetylase (HDAC) inhibitor, diminishes lymphoproliferation in the Fas -deficient MRL/lpr(-/-) murine model of autoimmune lymphoproliferative syndrome (ALPS). Exp Hematol 2009;37:487-94. 
Figure legend

Figure 1. Mice from the VPA model of autism present reduced numbers of CD3+CD4+ T-cells in subcutaneous lymph nodes. A) Representative FACS plots. B) Absolute number of $T$ lymphocytes $\left(x 10^{6}\right)$. C) Percentage of $T$ lymphocytes. Data are presented as means \pm standard error, with nine animals being analyzed per group.

Figure S1. The membrane density of CD3, CD4 and CD8, as shown through the corresponding median fluorescent intensity (MFI) on $\mathrm{T}$ lymphocytes, is not significantly altered in mouse subcutaneous lymph nodes, in the VPA model of autism. Data are presented as means \pm standard error, with four animals being analyzed per group. 